\title{
OPTIMIZATION OF DIMENSIONAL, SURFACE QUALITY AND MATERIAL REMOVAL RATE IN TURNING USING RESPONSE SURFACE METHODOLOGY AND DUELIST ALGORITHM
}

\author{
MAHA M. A. LASHIN ${ }^{1}$, AHMED M. GAAFER ${ }^{2}$ \& GHADA NAIF AL NEMER ${ }^{3}$ \\ ${ }^{1}$ Associated Professor, College of Engineering, Princess Nourah Bint Abdulrahman University, PNU, Saudi Arabia \\ ${ }^{2}$ Associated Professor, Department of Mechanical Engineering, Faculty of Engineering Shoubra, Banha University, Egypt \\ ${ }^{3}$ Assistant Doctor, Department of Mathematical Science, College of Science, Princess Nourah Bint Abdulrahman University,
}

PNU, Saudi Arabia

\begin{abstract}
Measuring the productivity and surface quality of turning process, mainly depends on performance parameters, like surface roughness, roundness error and rate of material removal. The main goal of this paper is to investigate the cut depth effect, cutting speed and turning process feed rate for AISI4145 alloy steel performance parameters. Experimentaly designed RSM (Response Surface Methodology) implmented to correlate between the cutting condition parameters and its turning process performance. The efficiency of the proposed models was tested through analysis of variance (ANOVA). A novel optimization technique, known as Duelist Algorithm is then applied for finding the optimal combination between the cutting process parameters and its effect on the process performance parameters. It is done by minimizing the values of both surface roughness and roundness error alongside maximizing the material removal rate. The optimal solutions were confirmed experimentally.

KEYWORDS: RSM, ANOVA, DA, Roughness \& Roundness
\end{abstract}

Received: Aug 11, 2019; Accepted: Aug 31, 2019; Published: Jan 30, 2020; Paper Id.: IJMPERDFEB202043

\section{INTRODUCTION}

Alloy Steel 4145 has a wide applications area at oil and gas industries, like pup joints, subs and drill collars. forged gears and shafts for hydraulic presses. Thus, the optimaization of the factors that have an effect on the surface quality and the productivity of 4145 steel alloy is inportant.

Optimizing the cutting processes, no matter what their type, is an important issue, as it affects the whole manufacturing process from different aspects. Turning process is one of the most important metal cutting operations utilized in producing round and cylindrical steel components.

The quality of the surface finish, dimensional tolerance and material removal rates are the three important factors that must be controlled in the turning process. The cutting process parameters (conditions) contain current speed, feed rate and depth of cut; using coolants will exert an impact on machining and surface quality conditions, which are material removal rates and surface roughness, respectively.

Roundness error of circular components and dimensional deviations of the product also affect the cutting process papameters. Kalpakjian et al., 2001. M. Rahman et al., 1986, optimized roundness error for achieveing the maximum possible material removal rate accurately. 
Yang et al., 1998, applied Taguchi approach to investigate the machining performance of high carbon S45C steel bars employing tungsten carbide tools. Also, optimization of cut depth values, cutting speed and feed rate in turning process and its effect on performance parameters, such as surface roughness and tool life were considered.

Influnce of cut depth, cutting speed and feed rate with the cutting time on metal matrix composites' turning was investigated by Davim et al., 2003.

Correlating surface coditions in terms of surface roughness $\left(R_{a}\right)$ and removal rate $\left(R_{t}\right)$ at different turning machining conditions for Aluminum-Silicon metal matrix composites, the multiple-linear mathematical models is used, Manna et al., 2004. Aslan et al., 2007 optimized cutting conditions of turning process for AISI 4140 steel with using aluminum oxide and titanium carbon nitride mixed with ceramic tool and analysis of variance ANOVA process that achieves something better defined as optimization process, M. Chandrasekaran et al., 2010. It involved three sections, which are model, objective function and optimization algorithm sections model.

Rangwala Dornfeld et al. 1989, predicting cutting performance during turning process done by an applied set of input patterns throught feedforward neural network. Natarajan et al., 2006 used particle swarm optimization for optimizing neural network prediction of tool life, to reduced training time by $50 \%$.

Li et al. 2000, employed neuro-fuzzy techniques to estimate the feed forced by measuring motor current by sensor in computer numerical control centire lathe machine.

Palanisamy et al., 2007, applied genetic algorithm technique to optimize cutting conditions of milling machining and minimize machining time.

Saravanan et al., 2007, minimized machining time done through optimal cutting speed and feed rate for turning process by using genetic algorithm.

R. V. Rao et al., 2009, used artificial bee colony to improve process conditions (cutting speed and surface roughness) of the electrical discharge machining.

Zheng et al., 2010 used particle swarm optimization for optimizing multi-pass turning process conditions and minimizing unit production cost.

The cuckoo search algorithm used by Ali, R. Yildiz et al., 2013 to improve machining conditions for milling process, compared between the results of using that algorithm and other evolutionary algorithms (particle swarm and genetic algorithm) appeared optimization of machining conditions.

Girish Kant et al., 2015, optimizining machining process conditions (4.65 m/sec cutting speed, $0.142 \mathrm{~mm} / \mathrm{tooth}$ feed rate and $0.67 \mathrm{~mm}$ depth of cut $)$ and minimize surface roughness $(0.099 \mu \mathrm{m})$ done based on neural network.

The response surface methodology and genetic algorithm were used by Kuldip S. Sangwan et al., 2017, for predicting the energy consumption along with the corresponding cutting parameters on turning process of AISI 1045 steel.

A novel algorithm called Jaya algorithm was applied by Rao et al., 2017 to optimize machining conditions for electrical discharge and electrochemical machining. The results showed a good performance for Jaya algorithm in comparison with other algorithms. 
Ingenetic algorithms in Tanveer et al., 2013, two ways used for developing, one individual to produce a new offspring and the other is an individual mutate into new duelist algorithm. DA (duelist algorithm) defined as the individual in population.

Totok R. Biyanto, et al., 2017, used duelists fight to determine the losers, winners and champions. DA tries to minimize the blind effect based on their classification.

In the present paper, duelist algorithm based on genetic algorithm is applied on AISI alloy steel 4145 due to its wide usage in industry. The optimization parameters are surface roughness, roundness error, and material removal, which appears at surface quality, dimensional quality and productivity measurement values. The study will also provide a reliable investigation on optimizing the machining process for AISI steel in industry, based only on the available required cutting ranges of the available machine tools. Moreover, it provides a full preview on employing such algorithm in different manufacturing optimization problems.

\section{MATERIAL AND METHODOLGY}

In the workpiece that is used in this experiment made of round bars from AISI 4145 alloy steel with diameter $25 \mathrm{~mm}$ and $80 \mathrm{~mm}$ length, as shown in figure 1.

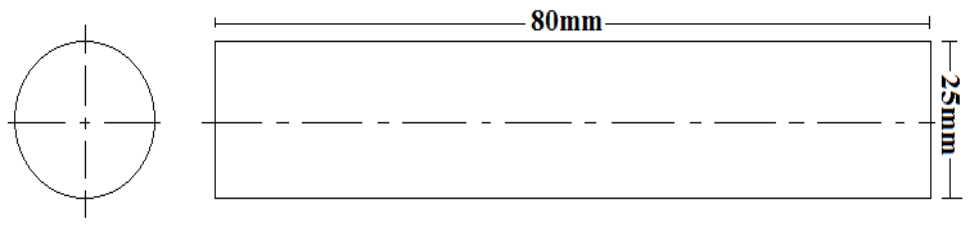

Figure 1: AISI 4145 Alloy Steel Bar.

The chemical composition and mechanical properties of AISI 4145 alloy steel explained in tables 1 and 2, respectively. A conventional center lathe with center distance of 1.5 meter, spindle speed range is (45- 2445 r.p.m), and feed range is $(0.08-0.38 \mathrm{~mm} / \mathrm{rev}$.).

Table 1: Chemical Composition of Steel 4145

\begin{tabular}{|c|c|c|c|c|c|} 
Element & $\mathbf{C}$ & $\mathbf{M n}$ & $\mathbf{C r}$ & $\mathbf{M o}$ & $\mathbf{S i}$ \\
\hline$\%$ & 0.44 & 0.89 & 0.88 & 0.23 & 0.2 \\
\hline
\end{tabular}

Table 2: Mechanical Properties of Steel 4145

\begin{tabular}{|c|c|c|c|c|}
\hline Properties & $\begin{array}{c}\text { Elastic Modulus } \\
(\mathbf{G P a})\end{array}$ & $\begin{array}{c}\text { Hardness } \\
(\text { Brinell) }\end{array}$ & $\begin{array}{c}\text { Shear Modulus } \\
(\mathbf{G P a})\end{array}$ & $\begin{array}{c}\text { Bulk Modulus } \\
(\mathbf{G P a})\end{array}$ \\
\hline Values & 200 & 308 & 80 & 140 \\
\hline
\end{tabular}

The tool used in this work was made of cemented carbide material inserts with specfication, as shown in table 3.

Table 3: Specfication of Cemented Carbide Tool

\begin{tabular}{|c|c|c|c|}
\hline $\begin{array}{c}\text { Rake Angle } \\
\boldsymbol{\alpha}\left({ }^{\boldsymbol{o}}\right)\end{array}$ & $\begin{array}{c}\text { Cutting Edge } \\
\text { Angle } \boldsymbol{\beta}\left({ }^{\boldsymbol{o}}\right)\end{array}$ & $\begin{array}{c}\text { Clearance } \\
\text { Angle } \boldsymbol{\gamma}\left({ }^{\boldsymbol{(}}\right)\end{array}$ & $\begin{array}{c}\text { Nose Radius } \\
\mathbf{r}(\mathbf{m m})\end{array}$ \\
\hline 5 & 80 & 7 & 0.4 \\
\hline
\end{tabular}

The surface roughness parameter $\left(\mathrm{R}_{\mathrm{a}}\right)$ of the workpiece after machining was measured with Surftest SJ-310 instrument, while the roundness testerTalyrond 73 - Taylor Hobson, S/no. 112/2802-0123, L.R. $=0.01 \mu \mathrm{m}$. 


\subsection{Uncertainty (U)}

Uncertainty evaluation dtermined in accordance with the JCGM 100:2008.

$$
\mathrm{U}= \pm 2.0 \mu \mathrm{m}
$$

$\mathrm{U}=$ uncertainty expanded using coverage factor $\mathrm{K}=2$, level confidence approximately $95 \%$.

\subsection{Traceability}

All equipments used for measurement are traceable to gauge blocks, which were calibrated by optical interferometer at KRISS traceable to SI units, certificate No: 05-03031-001.

\subsection{Environmental Conditions: $20^{0} \mathrm{C} \pm 1^{0} \mathrm{C}$}

Used for measuring roundness error.

\subsection{Experimental Design using RSM}

The experimental design is performed for realizing the effect of different parameter levels and a response as well as the interactions of the several factors. The experimental design for investigating effect of different turning process conditions (depth of cut, cutting speed and feed rate) on the machining characteristics (surface roughness, roundness error and the material removal rate), was done. In this paper, the experiments were designed using response surface method, employing central composite-second-order rotatable consisting of $2 \mathrm{k}$ factorial, where $\mathrm{k}$ represents the number of variables, the number of experiments $(\mathrm{N})$ can be found from the following equations:

$$
\begin{aligned}
& \mathrm{N}=\mathrm{n}_{\mathrm{c}}+\mathrm{n}_{\mathrm{a}}+\mathrm{n} \ldots, \\
& \mathrm{n}_{\mathrm{c}}=2 \mathrm{k} \ldots, \\
& \mathrm{n}_{\mathrm{a}}=2 \mathrm{k} \ldots,
\end{aligned}
$$

where

$\mathrm{n}_{\mathrm{c}}=$ number of corner points.

$\mathrm{n}_{\mathrm{a}}=$ number of axial points of the unit cube that constitutes of a central composite design.

Factors and factor levels summarized in table 4.

Table 4: The Factors and Factor Levels

\begin{tabular}{|c|c|c|}
\hline $\begin{array}{c}\text { Cutting Speed } \\
\text { (m/min) }\end{array}$ & $\begin{array}{c}\text { Feed Rate } \\
\text { (mm/rev.) }\end{array}$ & $\begin{array}{c}\text { Depth of } \\
\text { Cut (mm) }\end{array}$ \\
\hline 80 & 0.08 & 0.3 \\
\hline 115 & 0.16 & 0.6 \\
\hline 150 & 0.23 & 0.9 \\
\hline
\end{tabular}

\subsection{Methodology of Response Surface}

In that research, methodology of response surface used to determine the relation between turning process conditions (depth of cut, cutting speed and feed rate) and different machining criteria. Also, study the effect of turning process conditions on performance parameters (surface roughness, roundness error and the material removal rate). To do that, a response surface second-order polynomial mathematical models were developed, and a designed expert computer software was used for 
solving these polynomial mathematical equations to study the performance of affected parameters with change in cutting parameters values, as following sections describe.

\subsubsection{Mathematical Modeling for Surface Roughness}

Equation (6) explained the mathematical relation correlating between turning process, cutting process conditions and the surface roughness value. The results of the computing software for this equation is shown as in table 5 .

Surface Roughness $=+2.29587-0.016361 *($ cutting speed $)+5.94470 *($ feed rate $)-1.75990 *($ depth of cut $)$

$$
\begin{aligned}
& -0.034286 *(\text { cutting speed } * \text { feed rate })+(4.76190 \mathrm{E}-004) \\
& *(\text { cutting speed } * \text { depth of cut })+1.66667 *(\text { feed rate } * \text { depth of cut }) \\
& +(5.75411 \mathrm{E}-005) *(\text { cutting speed })^{2}-1.61095 *(\text { feed rate })^{2} \\
& +2.80631 *(\text { depth of cut })^{2}
\end{aligned}
$$

\subsubsection{Mathematical Modeling for Roundness}

The roundness affected with change in cutting parameters. It has been evaluated by computing the values of the different constants based on equation (7), using the designed expert computer software and the results of that equation is shown in table 5 .

$$
\begin{aligned}
\text { Roundness }=+ & 4.12174-0.045474 *(\text { cutting speed })+4.62907 *(\text { feed rate }) \\
& +0.47070 *(\text { depth of cut })+0.015238 *(\text { cutting speed } * \text { feed rate }) \\
& +(9.76190 \mathrm{E}-003) *(\text { cutting speed } * \text { depth of cut }) \\
& -6.55556 *(\text { feed rate } * \text { Depth of cut })+(9.62224 \mathrm{E}-005) *(\text { cutting speed }) \\
& \\
& -0.72950 *(\text { feed rate })^{2}+0.19011 *(\text { depth of cut })^{2}
\end{aligned}
$$

\subsubsection{Mathematical Modeling for Material Removal Rate (MRR)}

Based on equation (8), the change in MRR related to change in cutting parameters' values can be evaluated. The results of the computer written software is revealed in table 5 .

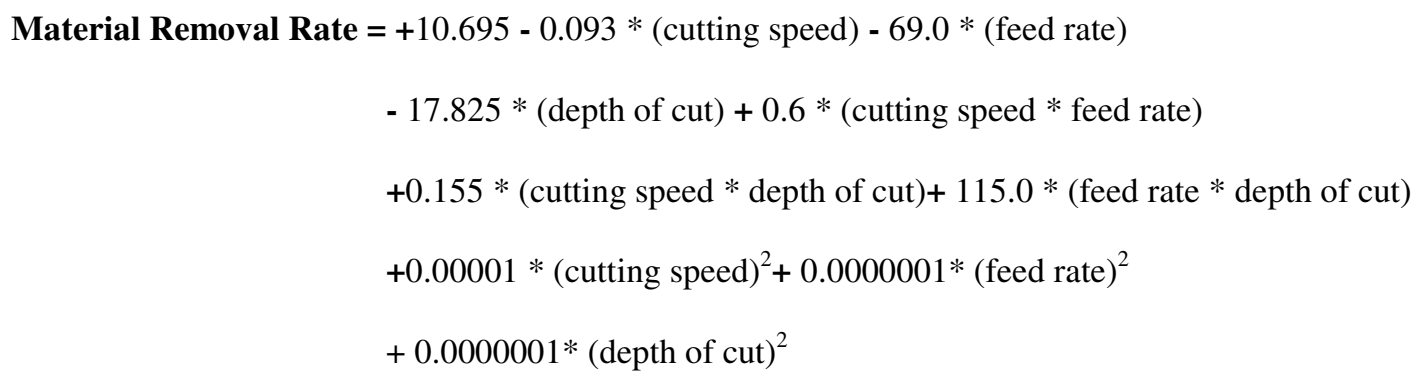


Table 5: Central Composite Rotatable Design, Different Controlling Parameters and Results

\begin{tabular}{|c|c|c|c|c|c|c|}
\hline Ex. no. & $\begin{array}{c}\text { Cutting } \\
\text { Speed } \\
(\mathrm{m} / \mathrm{min})\end{array}$ & $\begin{array}{c}\text { Feed Rate } \\
\text { (mm/rev) }\end{array}$ & $\begin{array}{c}\text { Depth of Cut } \\
\text { (mm) }\end{array}$ & $\begin{array}{c}\text { Surface } \\
\text { Roughness } \\
\text { (Ra) } \mu \mathrm{m}\end{array}$ & $\begin{array}{c}\text { Roundness } \\
(\mathbf{O}) \\
\mu \mathrm{m}\end{array}$ & $\begin{array}{c}\text { Material } \\
\text { Removal Rate } \\
\text { (MRR) } \\
\text { m }^{3} / \mathbf{m i n} \\
\end{array}$ \\
\hline $\mathbf{1}$ & 56 & 0.16 & 0.60 & 2.68 & 3.01 & 1.28723 \\
\hline 2 & 80 & 0.08 & 0.90 & 2.25 & 2.38 & 1.512 \\
\hline 3 & 115 & 0.03 & 0.60 & 1.42 & 1.29 & 0.545559 \\
\hline 4 & 115 & 0.16 & 0.60 & 1.37 & 1.51 & 2.9295 \\
\hline 5 & 174 & 0.16 & 0.60 & 1.04 & 1.09 & 4.57177 \\
\hline 6 & 115 & 0.16 & 1.10 & 3.24 & 2.3 & 5.39291 \\
\hline 7 & 80 & 0.23 & 0.30 & 1.66 & 2.35 & 1.449 \\
\hline 8 & 115 & 0.16 & 0.10 & 1.51 & 1.23 & 0.466094 \\
\hline 9 & 80 & 0.23 & 0.90 & 2.97 & 1.92 & 4.347 \\
\hline 10 & 150 & 0.23 & 0.30 & 1.19 & 0.92 & 2.898 \\
\hline 11 & 150 & 0.23 & 0.90 & 2.51 & 1.51 & 8.694 \\
\hline 12 & 80 & 0.08 & 0.30 & 1.1 & 1.61 & 0.504 \\
\hline 13 & 115 & 0.16 & 0.60 & 1.56 & 1.45 & 2.9295 \\
\hline 14 & 115 & 0.16 & 0.60 & 1.9 & 1.48 & 2.9295 \\
\hline 15 & 115 & 0.28 & 0.60 & 1.85 & 2.12 & 5.31344 \\
\hline 16 & 115 & 0.16 & 0.60 & 1.26 & 1.41 & 2.9295 \\
\hline
\end{tabular}

\subsection{Analysis of Variance (ANOVA)}

Analysis of variance (ANOVA) provides a statistical test of the means for several equal groups. Ch. Maheswara et al., 2010. It is useful for comparing (testing) three or more means (groups or variables) for statistical significance. The efficiency of the three models stated in the previous section are tested through (ANOVA). Analysis results appear at tables 6-8. Variance can be defined as the mean of squared deviations around mean, or sum of squared deviations around mean value divided to freedom degrees. Testing efficiency of a model is usually done by computing F-ratio, lack of fit to pure error and comparing with standard value. If standard values exceed the value of the F-ratio, then the proposed model is adequate. As it is clear from the results of analysis, the lack of fit F-value is not significant, which proves mathematical models' adequacy and demonstrate effects of different machining conditions on surface roughness, roundness and rate of material removal. The most effective factor on surface roughness is the cutting depth followed by speed of cut, as in table 6 .

Table 6: ANOVA for Surface Roughness Model

\begin{tabular}{|l|c|c|c|c|c|c|}
\hline \multicolumn{7}{|c|}{ Surface roughness } \\
\hline source & $\begin{array}{c}\text { Sum of } \\
\text { squares }\end{array}$ & df & $\begin{array}{c}\text { Mean } \\
\text { square }\end{array}$ & $\begin{array}{c}\text { F } \\
\text { Value }\end{array}$ & $\begin{array}{c}\text { p-value } \\
\text { prob>F }\end{array}$ & \\
\hline Model & 7.175 & 9 & 0.7973 & 8.9717 & 0.0010 & Significant \\
\hline $\begin{array}{l}\text { A-cutting } \\
\text { Speed }\end{array}$ & 1.113 & 1 & 1.1127 & 12.521 & 0.0054 & \\
\hline B-Feed & 0.481 & 1 & 0.4811 & 5.4135 & 0.0423 & \\
\hline $\begin{array}{l}\text { C-Depth of } \\
\text { cut }\end{array}$ & 4.535 & 1 & 4.5347 & 51.029 & $<0.0001$ & \\
\hline AB & 0.065 & 1 & 0.0648 & 0.7292 & 0.4131 & \\
\hline AC & 0.0002 & 1 & 0.0002 & 0.0023 & 0.9631 & \\
\hline BC & 0.011 & 1 & 0.0113 & 0.1266 & 0.7294 & \\
\hline A^2 & 0.072 & 1 & 0.0716 & 0.8058 & 0.3905 & \\
\hline B^2 & 0.001 & 1 & 0.0012 & 0.0133 & 0.9104 & \\
\hline C^2 & 0.919 & 1 & 09193 & 10.345 & 0.0092 & \\
\hline Residual & 0.889 & 10 & 0.0889 & & & \\
\hline Lack of fit & 0.517 & 5 & 0.1035 & 1.3943 & 0.3621 & Not \\
\hline Pure Error & 0.371 & 5 & 0.0742 & & & \\
\hline Cor Total & 8.064 & 19 & & & & \\
\hline
\end{tabular}


In table 7 , speed of cut is the most influential factor in roundness error followed by cutting depth.

Table 7: ANOVA for Roundness Model

\begin{tabular}{|l|c|c|c|c|c|c|}
\hline \multicolumn{7}{|c|}{ Roundness Model } \\
\hline \multicolumn{1}{|c|}{ Source } & $\begin{array}{c}\text { Sum of } \\
\text { Squares }\end{array}$ & df & $\begin{array}{c}\text { Mean } \\
\text { Square }\end{array}$ & $\begin{array}{c}\mathrm{F} \\
\text { Value }\end{array}$ & $\begin{array}{c}\text { p-value } \\
\text { Prob }>\mathrm{F}\end{array}$ & \\
\hline Model & 5.4785 & 9 & 0.6087 & 8.5085 & 0.0012 & significant \\
\hline A-Cutting Spe & 3.8266 & 1 & 3.8266 & 53.487 & $<0.0001$ & \\
\hline B-Feed & 0.3793 & 1 & 0.3793 & 5.3014 & 0.0441 & \\
\hline C-Depth of Cu & 0.7972 & 1 & 0.7972 & 11.143 & 0.0075 & \\
\hline AB & 0.0128 & 1 & 0.0128 & 0.1789 & 0.6813 & \\
\hline AC & 0.0841 & 1 & 0.0841 & 1.1748 & 0.3039 & \\
\hline BC & 0.1741 & 1 & 0.1741 & 2.4328 & 0.1499 & \\
\hline$A^{\wedge} 2$ & 0.2002 & 1 & 0.2002 & 2.7988 & 0.1253 & \\
\hline B^2 & 0.0002 & 1 & 0.0002 & 0.0034 & 0.9547 & \\
\hline C^2 & 0.0042 & 1 & 0.0042 & 0.059 & 0.8130 & \\
\hline Residual & 0.7154 & 10 & 0.0715 & & & not \\
\hline & & & & & & significant \\
\hline Lack of Fit & 0.5955 & 5 & 0.1191 & 4.9676 & 0.0516 & \\
\hline Pure Error & 0.1199 & 5 & 0.0240 & & & \\
\hline Cor Total & 6.1939 & 19 & & & & \\
\hline
\end{tabular}

In table 8, appeared the good effective way of cutting speed followed by cutting depth.

Table 8: ANOVA for Material Removal Rate Model

\begin{tabular}{|l|c|c|c|c|c|c|}
\hline \multicolumn{7}{|c|}{ Roundness Model } \\
\hline \multicolumn{1}{|c|}{ Source } & $\begin{array}{c}\text { Sum of } \\
\text { Squares }\end{array}$ & df & $\begin{array}{c}\text { Mean } \\
\text { Square }\end{array}$ & $\begin{array}{c}\mathrm{F} \\
\text { Value }\end{array}$ & $\begin{array}{c}\text { p-value } \\
\text { Prob }>\mathrm{F}\end{array}$ & \\
\hline Model & 5.4785 & 9 & 0.6087 & 8.5085 & 0.0012 & significant \\
\hline A-Cutting Spe & 3.8266 & 1 & 3.8266 & 53.487 & $<0.0001$ & \\
\hline B-Feed & 0.3793 & 1 & 0.3793 & 5.3014 & 0.0441 & \\
\hline C-Depth of Cu & 0.7972 & 1 & 0.7972 & 11.143 & 0.0075 & \\
\hline AB & 0.0128 & 1 & 0.0128 & 0.1789 & 0.6813 & \\
\hline AC & 0.0841 & 1 & 0.0841 & 1.1748 & 0.3039 & \\
\hline BC & 0.1741 & 1 & 0.1741 & 2.4328 & 0.1499 & \\
\hline$A^{\wedge} 2$ & 0.2002 & 1 & 0.2002 & 2.7988 & 0.1253 & \\
\hline B^2 & 0.0002 & 1 & 0.0002 & 0.0034 & 0.9547 & \\
\hline$C^{\wedge} 2$ & 0.0042 & 1 & 0.0042 & 0.059 & 0.8130 & \\
\hline Residual & 0.7154 & 10 & 0.0715 & & & \\
\hline & & & & & & not \\
Lack of Fit & 0.5955 & 5 & 0.1191 & 4.9676 & 0.0516 & significant \\
\hline Pure Error & 0.1199 & 5 & 0.0240 & & & \\
\hline Cor Total & 6.1939 & 19 & & & & \\
\hline
\end{tabular}

\subsection{Model Graphs}

\subsubsection{Turning Parametric Influence on Surface Roughness}

Relationship among cutting speed, feed rate and surface roughness at constant value of cutting depth $0.6 \mathrm{~mm}$, as in figure 2. Can see increasing of surface roughness with increasing feed rate and decreasing cutting speed. This is attributed to the increases in cutting forces and thus resulting in the reduction of the stability of the cutting operation and decrease in the quality of surface finish. 


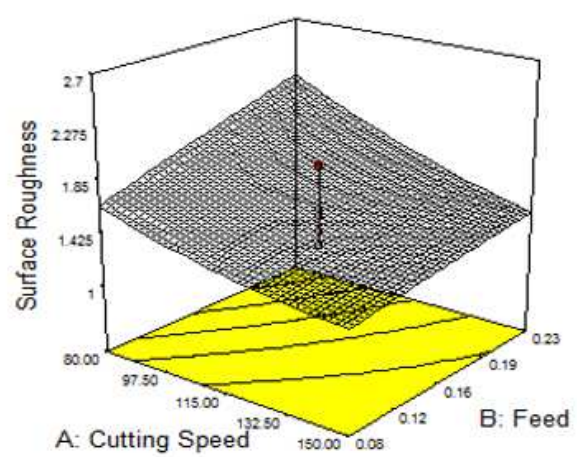

Figure 2: Change in Surface Roughness with Changing in Cutting Speed and Feed Rate.

Figure 3 reveals the relationship between surface roughness, depth and speed of cut at feed rate $0.16 \mathrm{~mm}$ constant value. It can be noted from the figure that the surface roughness increases on decreasing speed of cut due to increasing cutting force. Also, the roughness of the surface increases upon increasing the cutting depth, which is attributed to widening of the area of contact between the tip and the workpiece and thus changing the resulting force per unit length, which leads to chips' distortion while being removed.

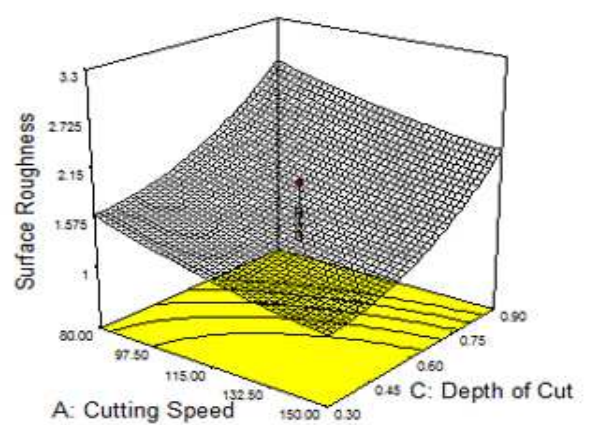

Figure 3: Influence of Speed of Cut and Cutting Depth on Surface Roughness

\subsubsection{Turning Parametric Influence on Roundness}

Figure 4 reveals the relation between roundness error, cutting speed and feed at 0.6-mm cutting depth constant value. Roundness error increases on decreasing the speed of cut and increasing the rate of feed, as in the figure. This is because decreasing the speed of cut and/or increasing feed rate, increase the force of cut for multivariate work-chuck-spindle system stiffness, which in turn affects the dimensional quality of the workpiece, as stated by M. Rahman and V. Naranayan, 1986.

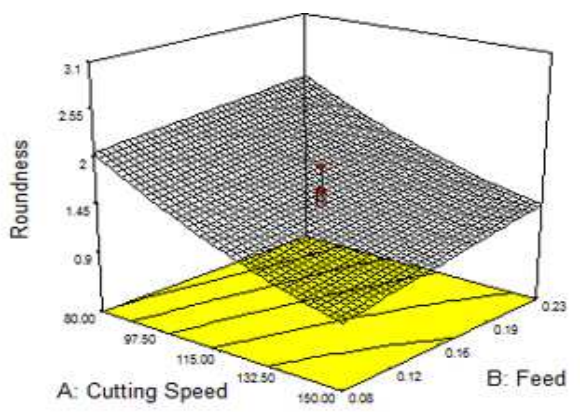

Figure 4: Influence of Speed of Cut and Feed Rate on Roundness 
Figure 5 reveals the relationship between roundness error, speed of cut and depth of cut at constant value of feed rate of $0.16 \mathrm{~mm}$. It can be noted from the figure that roundness error increases on decreasing the speed of cut and/or increasing cutting depth. Increasing the speed of cut is related to the increase in the cutting forces.

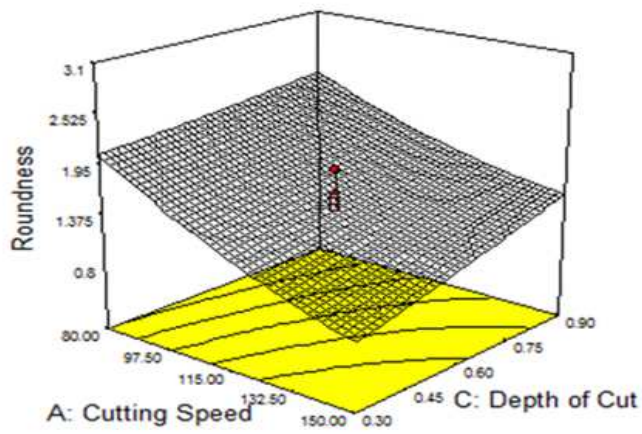

Figure 5: Relation between Speed of Cut, Cutting Depth and Roundness.

\subsubsection{Turning Parametric Influence on Material Removal Rate}

As it is clear from figure 6, increasing the speed of cut, feed rate and cutting depth increase the rate of material removal, as it follows the relation.

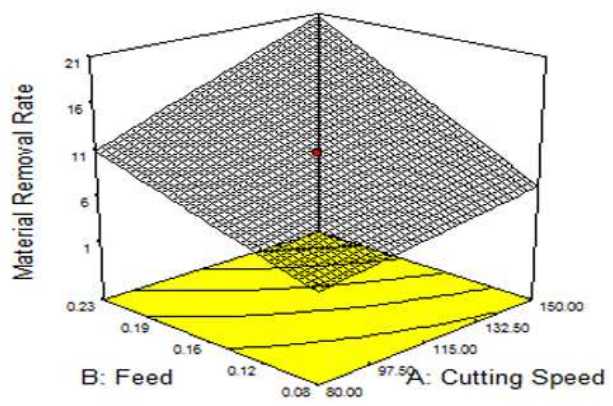

Figure 6: Relation between Speed of Cut, Feed Rate, Cutting Depth and Rate of Material Removal.

\section{DUELIST ALGORITHM}

Duelist Algorithm (DA) is a new evolutionary optimization algorithm proposed by Biyanto et al. [20] inspired by human fighting competitions. They showed that the DA is based on GA, but it is more efficient when compared to genetic, particle swarm optimization and imperialist competitive algorithms. DA contains a certain population of duelists in which each duelist would fight another one to determine the winner and loser, depending on each duelist's capability of fighting. Fighting capabilities are defined using objective function. This determination is for choosing the improvement that should be provided to them. Fighting capabilities consists of binaries with a specific length called skill set, resulting in new fighting capabilities. On the other hand, the loser will learn from the winner how to fight better. This training creates a new duelist from a lesser one with some new skill sets copied from the winner that beats them. Champions, which are the ones with the best fighting capabilities, are selected to maintain the best solution for each iteration. Champions would train new duelists as same as they are, which will add some more duelists to the tournament. To maintain the duelist's registered number fixed in the tournament, the worst fighting duelist's capabilities are eliminated. This process is repeated until stopping criteria is satisfied. 


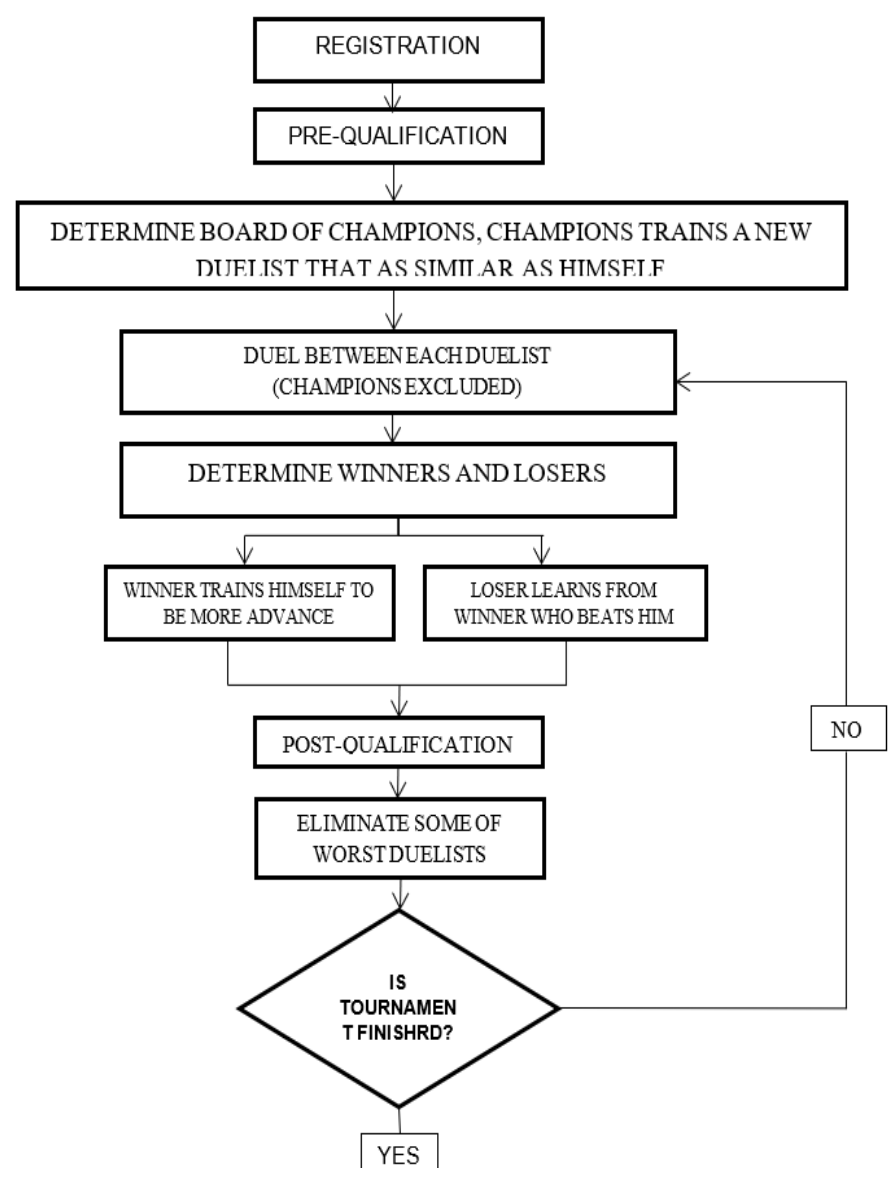

Figure7: Duelist Algorithm DA Flowchart.

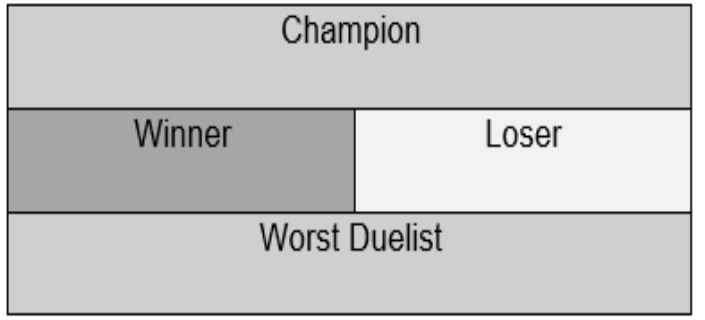

Figure 8: Duelist's Classification.

\subsection{Steps of Duelist Algorithm}

As revealed in figures 7 and 8 , the flowchart of DA explains its sequences as follows:

\subsubsection{Duelist Registration}

This is the first step of the algorithm in which each duelist is registered in a binary array called skillset.

\subsubsection{Prequalification Test}

Each duelist undergoes a prequalification test for evaluating its fighting capabilities depending on its skillset.

\subsubsection{Determination of Champions}

Keeping the best duelist competing depending on champion determination. Champion trains new individual for being well. Replacement champion in the competition and joining the next stage is done through a trained duelist. 


\subsection{Defining Each Duel Schedule}

Each duelist schedule is set randomly. Every competitor competed related to its capability of fighting and luck. The winners and losers are determined for each match. The duel uses simply logic. If competitor (A) has capability of fighting plus its luck greater than the competitor (B), then A will be winner and vice versa. Random function is used to determine the luck to avoid local optimum.

\subsection{Case Study}

In our work, the case study which the DA applied for turning process conditions, optimization is related to the models developed in section 4. For demonstration and validation duelist algorithm, an example is considered for objective function, which is used to minimize surface roughness and roundness, given by equations 6 and 7, respectively along with maximizing the material removal rate, given by equation 8 .

\subsection{Parameters Bound}

The three turning parameters (conditions) are considered in that the presented works are feeding rate, cutting depth and speed of cut. The upper - lower bounds of these conditions are given below:

$$
\begin{aligned}
& 80 \leq \text { cutting speed } \leq 150 \\
& 0.08 \leq \text { feed rate } \leq 0.23 \\
& 0.3 \leq \text { depth of cut } \leq 0.9
\end{aligned}
$$

The various steps of the duelist algorithm are now applied as follows:

Step 1: Defining the number of duelists in the competition as well as the fighting capabilities. In our problem, the number of population is 100 , which describes the number of duelists in the tournament and fighting capabilities as 50 , then the duelists are registered in the game; the registration is a binary array called skillset.

Step 2: Evaluating the competitors by setting a prequalification in terms of their fighting capabilities.

Step 3: The game starts between different duelists to classify the players into champions, winners and losers. The champions train new duelists to replace them in matches. The fitness function is specified as follows:

Fitness Function = Material Removal Rate Model - Surface Roughness Model - Roundness Model.

The negative sign is to indicate that both the Surface Roughness and Roundness Models shall be minimized, while Material Removal Rate Model is to be maximized.

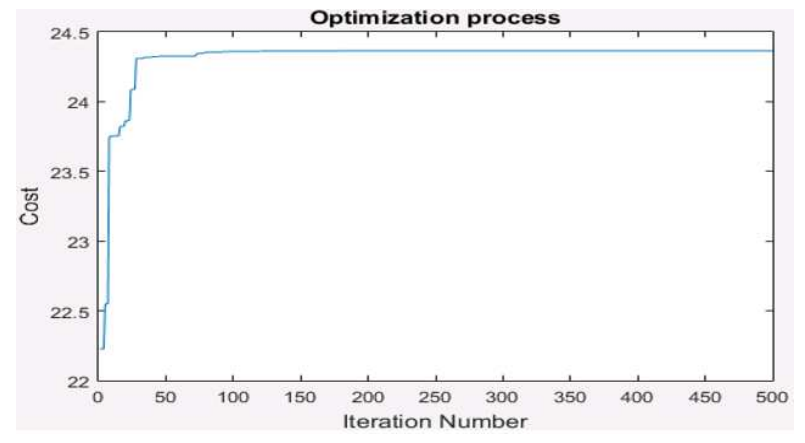

Figure 9: Convergence of Duelist Algorithm. 
Step 4: The game starts and the players compete, the match ends with winners and losers, and losers train from winners, who beat them and the winners develop qualifications. Worst duelists are eliminated to keep the number of populations fixed, and the process continues till the best solution is reached and maintained without change through the specified number of iterations. The game is the fitness function, while the players are the different values of process conditions that compete for getting the best possible values for the fitness function. Figure 9 explains convergence of duelist algorithm. The algorithm requires 75 to 100 iterations to reach the optimum value and table 9 reveals the corresponding optimum values.

Table 9: The Optimum Values of Process Parameters and the Corresponding Output

\begin{tabular}{|c|c|c|c|c|}
\hline $\begin{array}{c}\text { Process } \\
\text { Parameters }\end{array}$ & $\begin{array}{l}\text { Optimum } \\
\text { values }\end{array}$ & $\begin{array}{c}\text { Sulface } \\
\text { Roughness }\end{array}$ & Roundness & $\begin{array}{l}\text { Material Removal } \\
\text { Rate }\end{array}$ \\
\hline $\begin{array}{l}\text { Cutting Speed } \\
(\mathrm{m} / \mathrm{min})\end{array}$ & 149 & \multirow{3}{*}{2.1198} & \multirow{3}{*}{1.5120} & \multirow{3}{*}{27.9975} \\
\hline $\begin{array}{l}\text { Feed Rate } \\
(\mathrm{mm} / \mathrm{rev})\end{array}$ & 0.23 & & & \\
\hline $\begin{array}{l}\text { Depth of Cut } \\
\text { (mm) }\end{array}$ & 0.84 & & & \\
\hline \multicolumn{2}{|c|}{ Confirmation Test } & 2.14 & 1.58 & 28.8 \\
\hline \multicolumn{2}{|l|}{ Error \% } & 0.95 & 4.5 & 2.87 \\
\hline
\end{tabular}

\section{CONCLUSIONS}

The study presents modeling and optimizing of turning process conditions during dry turning process of AISI 4145 alloy steel using cemented carbide tool. The main objective considered is minimization of surface roughness and roundness error along with maximizing the material removal rate applying a novel technique known as duelist algorithm. A mathematical model depending on Response Surface Methodology (RSM) approach is developed to correlate between the speed of cut effects, rate of feeding and cutting depth of various machining process performance conditions, as roughness of the surface, roundness error and rate of removal material. Optimum values of the process conditions are then obtained due to developing Duelist optimization algorithm. The rate of convergence and solution accuracy are used as performance measures for the Duelist algorithm. Analysis of the resulting data appeared:

- Duelist algorithm possesses convergence rate of about 75 iterations to converge to optimal solution.

- Based on the limits employed in the experimental process, the maximum error was $4.5 \%$ between the validation data and the predicted data.

- The optimum turning conditions to obtain the minimum roughness of the surface and roundness values errors alongside maximum material removal rate values within proposed ranges.

- The Duelist algorithm is robust, simple in application and an effective optimization algorithm, which is used effectively in the optimization of multi-objective problems.

- The algorithm is employed to find the process conditions' optimal values for other machining processes.

- Duelist algorithm can be used in online optimization because of its convergence rate.

- Applying the Duelist algorithm can reduce the cost and time of operation by obtaining the optimum solution. 


\section{ACKNOWLEDGEMENT}

This research was funded by the Deanship of Scientific Research at Princess Nourah Bint Abdulrahman University through the fast-track research funding program.

\section{REFERENCES}

1. Kalpakjian, S. and Schmid, S. R., (2001). Manufacturing Engineering and Technology, International, Fourth edn. Prentice Hall Co., New Jersey, pp. $536-681$.

2. M. Rahman and V. Naranayan, (1986). Optimization of Error-of-Roundness in Turning Processes, Annals of the ClRP, Vol. $35 / 1 / 1986$.

3. Yang, W. H. and Tarng, Y. S., (1998). Design optimization of cutting parameters for turning operations based on the Taguchi method. J. Mater. Process. Technol., 84, 122 - 129.

4. Davim, J. P., (2003). Design of optimization of cutting parameters for turning metal matrix composites based on the orthogonal arrays. J. Mater. Process. Technol. 132, 340 - 344.

5. Rajyalakshmi, M., \& Babu, P. S. Optimization of process parameters for pocket milling of al7075 using response surface methodology.

6. Manna, A. and Bhattacharyya, B., (2004). Investigation for optimal parametric combination for achieving better surface finish during turning of Al/SiC-MMC. Int. J. Adv. Manuf. Technol. 23, 658 - 665.

7. Aslan, E., Camuscu, N. and Birgoren, B., (2007). Design optimization of cutting parameters when turning hardened AISI 4140 steel (63 HRC) with Al2O3 +TiCN mixed ceramic tool. Mater. Des. 28, $1618-1622$.

8. M. Chandrasekaran, M. Muralidhar, C. Murali Krishna and U. S. Dixit, (2010). Application of soft computing techniques in machining performance prediction and optimization: a literature review. Int. J. Adv. Manuf. Technol. 46:445 - 464.

9. Rangwala, S. S. and Dornfeld, D. A., (1989). Learning and optimization of machining operations using computing abilities of neural networks. IEEE Trans. Syst. Man. Cybern. 19:299 - 314.

10. Natarajan, U., Saravanan, R. and Periasamy, V. M., (2006). Application of particle swarm optimization in artificial neural network for prediction of tool life. Int. J. Adv. Manuf. Technol. 28:1084 - 1088. doi:10.1007/s00170-004-2460-5.

11. Li X, Venuvinod, P. K. and Chen, M. K., (2000). Feed cutting force estimation from the current measurement with hybrid learning. Int. J. Adv. Manuf. Technol. 16:859 - 862. doi:10.1007/s001700070002.

12. Kushwaha, D., Ranjan, R., Kushawaha, V. K., \& Tariq, M. Evaluation and optimization of cutting parameters, for turning of en-8 steel: a Taguchi approach.

13. Palanisamy, P., Rajendran, I. and Shanmugasundaram, S. (2007). Optimization of machining parameters using genetic algorithm and experimental validation for end-milling operations. Int. J. Adv. Manuf. Technol., $32(7$ - 8), 644 - 655.

14. Saravanan, R. and Janakiraman, V., (2007). Study on reduction of machining time in CNC turning centre by genetic algorithm. Paper presented at the Proc. - Int. Conf. Computational Intelligence and Multimedia Applications, ICCIMA 2007, $1,481-486$.

15. Rao, R. V., and Pawar, P. J., (2009). Modeling and optimization of process parameters of electrical wire discharge machining. Proc. Institution of Mechanical Engineers, Part B: J. Eng. Manuf., 223(11), 1431 - 1440. 
16. Zheng, L. Y. and Ponnambalam, S. G., (2010). Optimization of multi-pass turning operations using particle swarm optimization. Paper presented at the ISMA. 10 - 7th Int. Symp. Mechatronics and its Applications, 1 - 6.

17. Yildiz, A. R., (2013). Cuckoo search algorithm for the selection of optimal machining parameters in milling operations. Int. J. Adv. Manuf. Technol. 64: 55. doi:10.1007/s00170-012-4013-7.

18. Yunus, M. О. Н. A. M. M. E. D., \& Alsoufi, M. S. (2015). A statistical analysis of joint strength of dissimilar aluminium alloys formed by friction stir welding using taguchi design approach, anova for the optimization of process parameters. IMPACT: International Journal of Research in Engineering \& Technology (IMPACT: IJRET), 3(7), 63-70.

19. Girish Kant and Kuldip Singh Sangwan, (2015). Predictive Modeling and Optimization of Machining Parameters to Minimize Surface Roughness using Artificial Neural Network Coupled with Genetic Algorithm. Procedia CIRP, 31,453 - 458.

20. Kuldip Singh Sangwan and Girish Kant, (2017). Optimization of Machining Parameters for Improving Energy Efficiency using Integrated Response Surface Methodology and Genetic Algorithm Approach. Procedia CIRP, 61, 517-522.

21. Rao, R. V., D. P. Raia, and Joze Balic, (2017). A multi-objective algorithm for optimization of modern machining processes. Eng. Appl. Artif. Intell. 61, 103-125.

22. Tanveer Hosssain Bhuiyan and Imtiaz, Ahmed, 2013. Optimization of cutting parameters in turning process, J. Prod. Eng., 16, $11-19$.

23. Totok R. Biyanto, Kukuh Gharyta, Gabriella, P. Dienanta, Nanda E. Tama, Arfiq I. Abdillah, Matradji, Hendra Cordova, Tita Oxa Anggrea and Sonny Irawan, 2017. Optimization of Mud Injection Pressure in Oil Drilling Using Duelist Algorithm, Selected topics on improved oil recovery, transactions of the international conference on improved oil recovery.

\section{AUTHORS PROFILE}

Dr. Maha Mahmoud Aly Lashin, Assistant Professor Degree in mechanical design and production. Ph.D. degree in Artificial Intelligent from Cairo university-Egypt, Assoc. Prof. at PNU, College of Engineering, Kingdom of Saudi Arabia. Supervision of Master and Philosophy Doctor Degrees for Students of Engineering Colleges for example, Smart Memory Alloy Development for the Effective Use of Control Systems, Diagnosis of Machinery Malfunctions by Analyzing the Vibrations Using Genetic Algorithms, Modeling and simulation of the Static and Dynamic Performance of Sandwich Beams, Automated Monitoring and Measuring Improvement of Production System Performance and Control of Air Handling Unit as a Method of Reducing Power Consuming. Published more than 30 papers in international journals at fields of Automatic Control, Mechanical Vibration Analysis, Artificial Intelligent and Composite Materials.

Dr. Ahmed Gaafer Mohamed, Associated Prof. at faculty of engineering-Banha university, Mechanical branch, Prof. of Theory of machines, Quality Control, Production Technology, Materials Technology, Production planning, Measurement \& instrumentation and Nano material. Scientific field, Manufacturing Engineering, Metal Matrix Composites (MMCs) Metal Matrix Nanocomposites (MMNCs) - Polymeric Matrix Composites (PMCs) - Biomaterials - Nanomaterials Friction Stir Welding (FSW) - Friction Stir Processing (FSP) - Functionally Graded Materials (FGM). Stir Casting Rheocasting - Powder Metallurgy (PM) - Squeeze Casting - Friction Stir Welding (FSW) - Friction Stir Processing (FSP) - Non-conventional machining. Mechanical Properties - Microstructural Properties - Tribological Characteristics Corrosion resistance - Machinability. 
Dr. Ghada Al Nemer, Saudi, Assistant Professor Degree in Functional Analysis, Mathematics department, Kau, Saudi Arabia. GhadaAlNemer currently works at the Department of Mathematical Science, Princess Nourahbint Abdulrahman University (PNU). Ghada is the Vice Dean for educational affairs for college of Engineering in PNU. Ghada does research in Analysis, Mathematical modeling, Topology, Fixed Point Theory, Best Proximity Point Theory, Differential Equations. 
